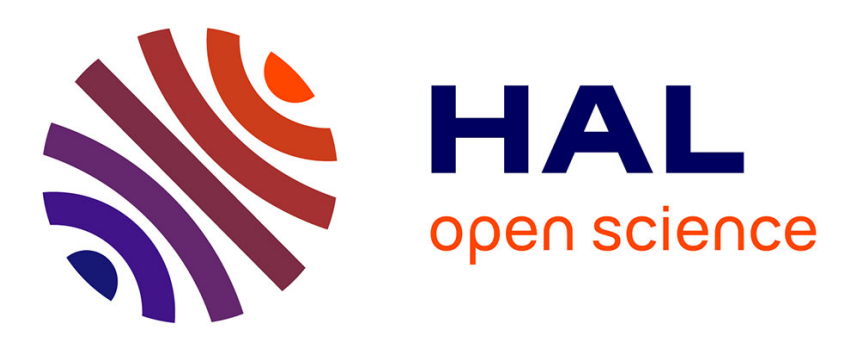

\title{
The influence of polymer impregnation ratios on the surface properties of fumed silicas as determined by inverse gas chromatography
}

\author{
Marie-Pierre Comard, Rachel Calvet, H Balard, John A. Dodds
}

\section{To cite this version:}

Marie-Pierre Comard, Rachel Calvet, H Balard, John A. Dodds. The influence of polymer impregnation ratios on the surface properties of fumed silicas as determined by inverse gas chromatography. Colloids and Surfaces A: Physicochemical and Engineering Aspects, 2004, 232 (2-3), pp.269-274. 10.1016/j.colsurfa.2003.11.005 . hal-01680771

\section{HAL Id: hal-01680771 https://hal.science/hal-01680771}

Submitted on 20 Nov 2018

HAL is a multi-disciplinary open access archive for the deposit and dissemination of scientific research documents, whether they are published or not. The documents may come from teaching and research institutions in France or abroad, or from public or private research centers.
L'archive ouverte pluridisciplinaire HAL, est destinée au dépôt et à la diffusion de documents scientifiques de niveau recherche, publiés ou non, émanant des établissements d'enseignement et de recherche français ou étrangers, des laboratoires publics ou privés. 


\title{
The influence of polymer impregnation ratios on the surface properties of fumed silicas as determined by inverse gas chromatography
}

\author{
M.-P. Comard ${ }^{\text {a }}$, R. Calvet ${ }^{\mathrm{a}, *}$, H. Balard ${ }^{\mathrm{b}}$, J.A. Dodds ${ }^{\mathrm{a}}$ \\ ${ }^{a}$ Ecole des Mines d'Albi Carmaux, Campus Jarlard, Route de Teillet, 81013 Albi, France \\ ${ }^{\mathrm{b}}$ ICSI, 15 rue Starcky, B.P. 2488, 68057 Mulhouse, France
}

\begin{abstract}
The evolution of the surface properties of two types of fumed silica impregnated with different amounts of different polymers (polyethyleneglycol (PEG), polyvinylchloride (PVC), polyvinylmethylketon (PVMK) or polystyren (PS)) has been studied by inverse gas chromatography at infinite dilution. IGC-ID is a convenient method for the examination of the surface properties of a solid in which molecular probes are injected in very small amounts so that they mainly interact with sites of highest energy. The impregnation of silica with increasing polymer ratios leads to the progressive killing of these sites, allowing the probes to access the less energetic free sites. The polymers were chosen on the basis of their acidic or basic properties. A basic polymer, like PEG or PS, should first interact with the silanol groups, whereas an acidic polymer should interact preferentially with siloxane bridges. What behaviour will be adopted by an amphoteric polymer, such as PVMK?

IGC-ID also allows a fine estimate of the number of monomer units per nanometer square necessary to form a polymer monolayer at the surface of the solid. Finally, we have followed the evolution of the glassy transition temperature of the adsorbed polymer, with the PVC impregnation ratios on a silica. Correlatively, the enthalpies of adsorption below and above this critical temperature were determined. Hence, we will demonstrate that it will be possible to examine the evolution of the surface properties from the point of view of the polymer layer adsorbed on the silica surface.
\end{abstract}

Keywords: Silica; Inverse gas chromatography; Polymer; Surface energy; Glassy transition temperature

\section{Introduction}

The principle of IGC is very simple [1]. A column is filled with the powder material under test and molecules with clearly identified features called probes are injected into the column. The retention time and peak elution profiles of the probes give information on their interactions with the surface of the solid and on the characteristics of both the surface of the solid and the probe. The complexity of these interactions depends on the amounts of probe injected. There are two different IGC techniques: infinite dilution (IGC-ID) or at finite solute concentration. In IGC-ID, very small amounts of probe are injected into the column in such a way that the interactions between probe molecules can be considered to be negligible. Only the interactions between the surface of the solid and an isolated probe molecule exist. Depending on the nature of the probe, IGC-ID gives access to different

* Corresponding author.

E-mail address: calvet@enstimac.fr (R. Calvet). properties of the surface of the solid. The injection of a series of linear alkanes allows the determination of the dispersive component of the surface free energy $\left(\gamma_{\mathrm{s}}^{\mathrm{d}}\right)$ of the solid contained in the column. This parameter represents the London interactions between the probe and the solid surface.

A major limitation of IGC-ID appears in the case of a heterogeneous surface because the technique only gives access to apparent thermodynamic data and is mainly sensitive to the presence of high energy adsorption sites. Here, we will try to take advantage of this limitation by coupling IGC-ID with a progressive impregnation of the sites having the highest energies by adsorption of a polymer. This polymer will progressively saturate the more active sites by preferential adsorption, causing the probes to access the less energetic free sites. So, by increasing the amount of polymer added to the solid, the probes will access different energy sites on the surface of the solid. This method has first been applied to talc [2]. The results obtained gave interesting information, in particular allowed to distinguish the two kinds of surface on talc, the basal surfaces and the lateral surfaces. In this 
Table 1

Surface area and fractal dimension of fumed silica samples (3)

\begin{tabular}{llllll}
\hline $\begin{array}{l}\text { Silica } \\
\text { samples }\end{array}$ & $\begin{array}{l}S_{\mathrm{N} 2} \\
\left(\mathrm{~m}^{2} / \mathrm{g}\right)\end{array}$ & $\begin{array}{l}\mathrm{S}_{\mathrm{CTAB}} \\
\left(\mathrm{m}^{2} / \mathrm{g}\right)\end{array}$ & $R_{\mathrm{CTAB} / \mathrm{N} 2}$ & $D_{\mathrm{CTAB} / \mathrm{N} 2}$ & $\mathrm{OH} / \mathrm{nm}^{2 *}$ \\
\hline N20 & 199 & 200 & 1.01 & 2.0 & 1.8 \\
T30 & 300 & 245 & 0.82 & 2.5 & 1.8 \\
\hline
\end{tabular}

* The number of $\mathrm{OH} / \mathrm{nm}^{2}$ was determined by acid-base titration.

paper, the same method is used with silica to try to distinguish two different functional groups on the same surface.

\section{Materials and methods}

Two silica samples, supplied by Wacker GmbH have been used in the experiments, and were described in previous papers [3-6]. Their characteristics are presented in Table 1. As proved by the comparison of the nitrogen and CTAB adsorptions, the HDK-N20 silica can be considered to be flat at the molecular scale as evidenced by its surface fractality equal to 2 . Whereas the slightly microporous HDK-T30 silica presents a surface roughness corresponding to a surface fractality equal to 2.5. This observation was confirmed by size exclusion inverse gas chromatography based on the comparison of elution behaviour of linear alkanes and their cyclic or branched isomers [5]. Solutions of a polymer (PEG or PS or PVC or PVMK described in Table 2) at different concentrations are mixed with a given mass of silica. An ex- ample of the polymer concentration, the mass of the silica and the ratio polymer/silica is presented in Table 3 for the PEG. After evaporation of the solvent $\left(\mathrm{CH}_{2} \mathrm{Cl}_{2}\right.$ for PEG, PS or PVMK and THF for PVC) a stainless steel tube is filled with the impregnated silica. The columns are conditioned at $120^{\circ} \mathrm{C}$ overnight and analysed at $100{ }^{\circ} \mathrm{C}$.

The monomer unit coverage ratios expressed in monomer unit per nanometer square were calculated using the following formula:

$n_{\mathrm{MU}}=\frac{6023 \tau}{M_{\mathrm{MU}} S}$

where $\tau(\%)$ is the coverage ratio expressed as a percentage, $n_{\mathrm{MU}}$ is monomer unit number per nanometer square of silica, $M_{\mathrm{MU}}$ is molecular weight of the monomer unit of interest, $S$ is specific area of powder in meter per gram.

Two Hewlett-Packard 6890 gas chromatographs, each fitted with two flame ionisation detectors were used. The carrier gas was helium. The injector and detector were heated to $150{ }^{\circ} \mathrm{C}$.

\section{Results and discussion}

3.1. Study of the influence of the impregnation ratio on the dispersive component $\gamma_{\mathrm{s}}^{\mathrm{d}}$

Fig. 1 displays the variation of $\gamma_{\mathrm{s}}^{\mathrm{d}}$ with respect to the number of monomer units of PEG $20 \mathrm{M}$ per $\mathrm{nm}^{2}\left(\mathrm{MU} / \mathrm{nm}^{2}\right)$

Table 2

Mean characteristics of the polymers

\begin{tabular}{lllll}
\hline Polymer & Abbreviation & Supplier & Molecular weight (g/mol) & Density \\
\hline Polyethyleneglycol & PEG & Fluka & 20,000 & 1.24 \\
Polystyren & PS & Aldrich & 23,0000 & 1.05 \\
Polyvinylchloride & PVC & Aldrich & 43,000 & 1.42 \\
Polyvinylmethylketon & PVMK & Aldrich & 50,0000 & 1.12 \\
\hline
\end{tabular}

Table 3

Preparation of the samples with T30 silica and PEG

\begin{tabular}{|c|c|c|c|c|c|}
\hline $\begin{array}{l}\text { Concentration of the } \\
\text { PEG in } \mathrm{CH}_{2} \mathrm{Cl}_{2} \\
\text { solution }(\mathrm{mg} / \mu \mathrm{l})\end{array}$ & $\begin{array}{l}\text { Volum of PEG in } \\
\mathrm{CH}_{2} \mathrm{Cl}_{2} \text { added to } \\
\text { the silica }(\mu \mathrm{l})\end{array}$ & $\begin{array}{l}\text { Mass of } \\
\text { silica }(\mathrm{g})\end{array}$ & $\begin{array}{l}\tau, \text { ratio } \\
\text { polymer/silica } \\
(\mathrm{mg} / \mathrm{g})\end{array}$ & $\begin{array}{l}\tau, \text { ratio } \\
\text { polymer/silica } \\
(\%)\end{array}$ & $\begin{array}{l}n_{\mathrm{UM}} \text { of PEG } \\
\text { on the surface } \\
\left(\mathrm{UM} / \mathrm{nm}^{2}\right)\end{array}$ \\
\hline 0.01 & 0 & 1.0143 & 0.000 & 0.000 & 0.000 \\
\hline 0.01 & 200 & 1.0156 & 1.973 & 0.197 & 0.135 \\
\hline 0.01 & 600 & 1.0403 & 5.778 & 0.578 & 0.395 \\
\hline 0.04 & 250 & 1.0457 & 9.575 & 0.958 & 0.655 \\
\hline 0.01 & 2,000 & 1.0315 & 19.425 & 1.943 & 1.330 \\
\hline 0.01 & 3,000 & 1.0613 & 28.320 & 2.832 & 1.938 \\
\hline 0.01 & 5,000 & 1.0453 & 47.922 & 4.792 & 3.280 \\
\hline 0.01 & 8,000 & 1.0799 & 74.218 & 7.422 & 5.080 \\
\hline 0.01 & 10,000 & 1.0060 & 99.587 & 9.959 & 6.816 \\
\hline 0.01 & 15,000 & 1.0578 & 142.066 & 14.207 & 9.723 \\
\hline 0.01 & 20,000 & 1.0485 & 191.102 & 19.110 & 13.080 \\
\hline 0.01 & 30,000 & 1.0119 & 297.020 & 29.702 & 20.329 \\
\hline 0.04 & 12,500 & 1.0439 & 479.590 & 47.959 & 32.825 \\
\hline 0.04 & 25,000 & 1.0455 & 957.712 & 95.771 & 65.549 \\
\hline
\end{tabular}




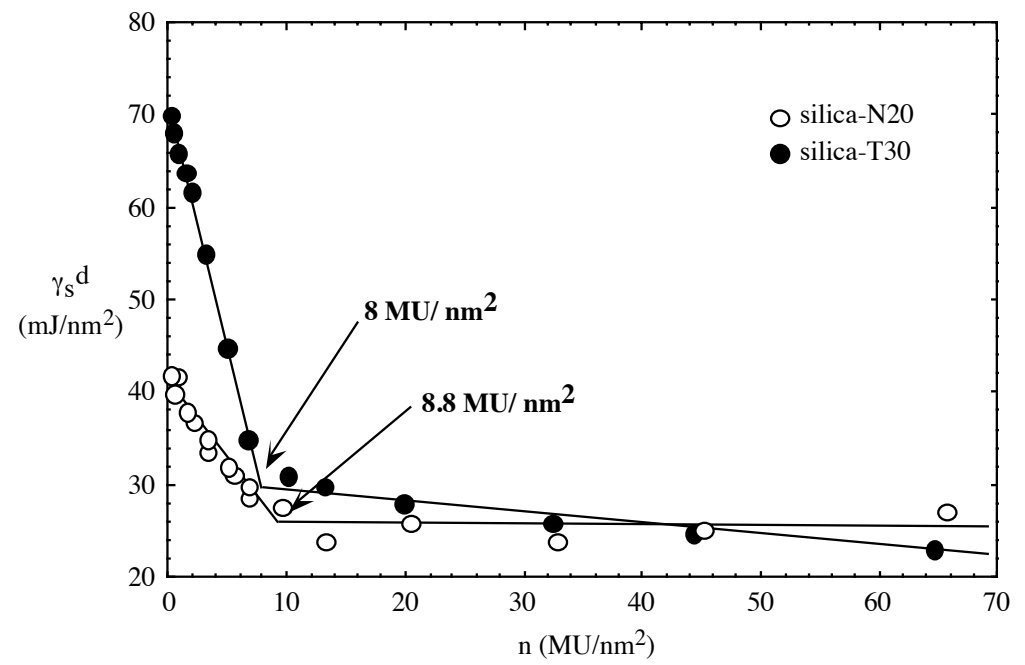

Fig. 1. Variation of the dispersive component of the surface energy $\left(\gamma_{\mathrm{s}}^{\mathrm{d}}\right)$ of the N20 and T30 silicas, impregnated with different ratios of PEG $20 \mathrm{M}$.

obtained by impregnation of the two fume silicas. The curve can be divided into two parts with a break point at $8 \mathrm{MU}$ for the T30 silica and slightly more for the N20 silica. The first part of the curve corresponds to the progressive formation of a monolayer of polymer at the surface of the silica. The values at the break points can be interpreted, as the amount of polymer required to form a monolayer of $\mathrm{MU}$ on the surface of the solid. It would appear that the structure of the silica surface slightly influences this value. A smooth surface requires a greater amount of polymer to reach the monolayer than does a microporous surface. It may be supposed that the polymer has more difficulty to penetrate roughnesses in the surface. In the second part of the curves, when the impregnation ratio is higher than the critical ratio, that is to say when the $\gamma_{\mathrm{s}}^{\mathrm{d}}$ reaches a plateau or decreases more slowly, the polymer forms a thick multilayer film at the surface of the solid.

Results obtained with the T30 silica have a much wider spread than those obtained with N20 silica. The $\gamma_{\mathrm{s}}^{\mathrm{d}}$ varies from 70 to $25 \mathrm{~mJ} / \mathrm{m}^{2}$ for the T30 and from 40 to $25 \mathrm{~mJ} / \mathrm{m}^{2}$ for the $\mathrm{N} 20$. We therefore concentrate on the results obtained for T30.

The same approach was used with other polymers: PS, PVC and PVMK. The first was chosen for its basic character compared to PEG, the second because it is acidic, the third as it is both acidic and basic. The evolutions of $\gamma_{\mathrm{s}}^{\mathrm{d}}$ obtained by impregnation of T30 silica with these four polymers are presented in Fig. 2.

Whatever the acidic or basic character of the polymer, the $\gamma_{\mathrm{s}}^{\mathrm{d}}$ curves present the same general form with one break point on each curve. The polymer is unable to interact selectively with any given kind of site without having an effect on the other [7].

However, it can be seen that each curve is different. Specifically, the amount of polymer necessary to reach the break point depends on the polymer. This difference can be attributed to the chemical structure of the polymer and, in particular, to its conformation on the surface of the solid.

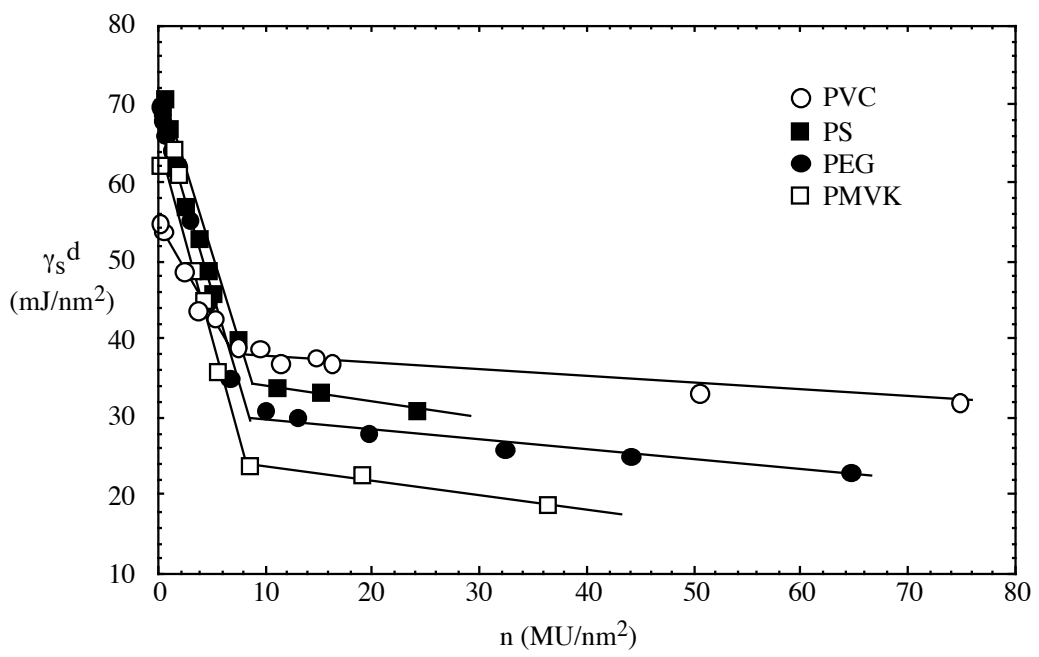

Fig. 2. Variation of the dispersive component of the surface energy $\left(\gamma_{\mathrm{s}}^{\mathrm{d}}\right)$ of the T30 silica impregnated with different ratios of PEG, PS, PVC and PVMK. 
Table 4

Number of monomer unit per nanometer square necessary to form a monolayer at the surface of the solid for each polymer (PEG, PVC, PVMK and PS) found by IGC and calculation

\begin{tabular}{lllll}
\hline Polymer & $\begin{array}{l}F_{\text {IGC }} \\
\left(\mathrm{MU} / \mathrm{nm}^{2}\right)\end{array}$ & $\begin{array}{l}F_{\text {theo }} \\
\left(\mathrm{MU} / \mathrm{nm}^{2}\right)\end{array}$ & $\begin{array}{l}F_{\text {theo }}+20 \% \\
\left(\mathrm{MU} / \mathrm{nm}^{2}\right)\end{array}$ & $\begin{array}{l}F_{\mathrm{IGC}} /\left(F_{\text {theo }}+20 \%\right) \\
\left(\mathrm{MU} / \mathrm{nm}^{2}\right)\end{array}$ \\
\hline PEG & 8.0 & 6.6 & 7.9 & 1.01 \\
PVC & 6.6 & 5.7 & 6.8 & 0.97 \\
PVMK & 7.7 & 4.5 & 5.4 & 1.42 \\
PS & 8.0 & 3.3 & 4.0 & 2.00 \\
\hline
\end{tabular}

Another difference is the value of $\gamma_{\mathrm{s}}^{\mathrm{d}}$ for high impregnation ratios. This energy is the energy of the polymer alone because the polymer covers the whole surface of the solid.

The number of monomer unit per namometer square necessary to form a monolayer at the surface of the solid for each polymer is given in Table 4 . This number will be called $F$, which stands for monolayer fraction. The value of $F$ for each polymer found by IGC using the previous graph, are listed in the second column. However, if we consider that one monomer unit is a cube and that each monomer unit is independent, $F$ can also be estimated by a simple calculation which takes the density and the molecular weight of one monomer unit into account (column 3).

$$
F_{\text {theo }}=\sqrt{\frac{6.02 d}{M_{\mathrm{MU}} 10^{-2}}}
$$

where $F_{\text {theo }}$ is the monomer unit monolayer fraction, theoretical number of monomer unit per namometer square of silica necessary to form a monomer unit monolayer, $d$ is density of the polymer and $M$ is molecular weight of the polymer monomer unit.

It is well known that this calculation underestimates this value by about $20 \%$. So, if we compare the results obtained

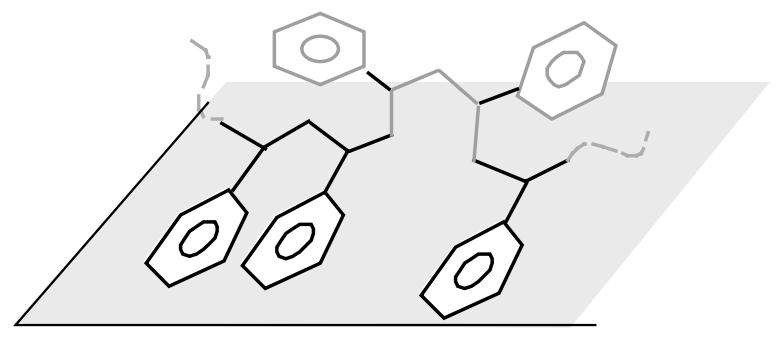

Fig. 3. Schematic representation of the loops of PS at the surface of the silica T30.

by IGC and those obtained by the calculation and add $20 \%$ (column 4), we find the last column of Table 4.

The results obtained by IGC are in very good agreement with those obtained by calculation if the chains of the polymer are linear and flexible as for PEG or if the volume of the branch is not too great as in PVC. In spite of their opposing chemical characters, these two polymers adopt the same conformation at the surface of the solid. These macromolecules can form a uniform film of thickness quite equal to the monomer unit dimension.

This is obviously not the case for PVMK and PS. The greater the volume of the branch, the bigger is the difference between the IGC results and the calculation. Because of the bulkiness of the monomer unit, these polymers form a film with a thickness greater than the thickness of $1 \mathrm{MU}$. For example, all the cycles of PS cannot be adsorbed flat on the surface, so they probably form loops (Fig. 3).

The comparison between $F$ found by IGC and determined by calculation demonstrates that PS and PEG do not adopt the same conformation at the surface of the silica. The evolution of the specific surface of the T30 silica impregnated with different ratios of PEG and PS leads to the same conclusion (Fig. 4). These evolutions depend on the polymer, and even if at $8 \mathrm{MU} / \mathrm{nm}^{2}$ the specific surfaces are the same

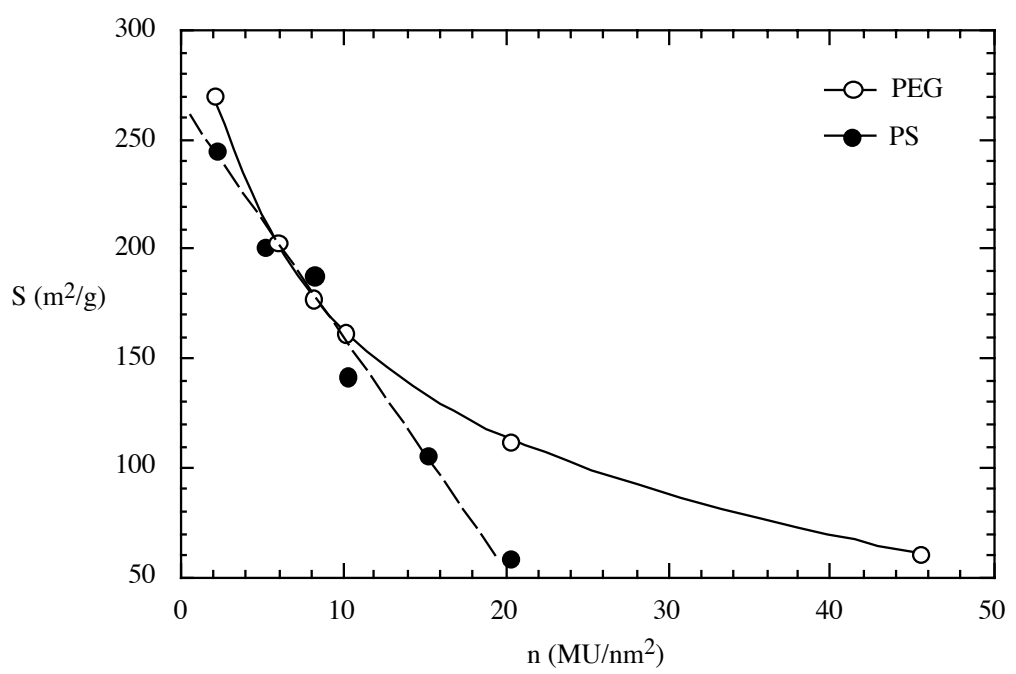

Fig. 4. Evolution of the specific surface of the T30 silica impregnated with different ratios of PEG and PS as measured with a micromeritics ASAP 2010 using nitrogen. 


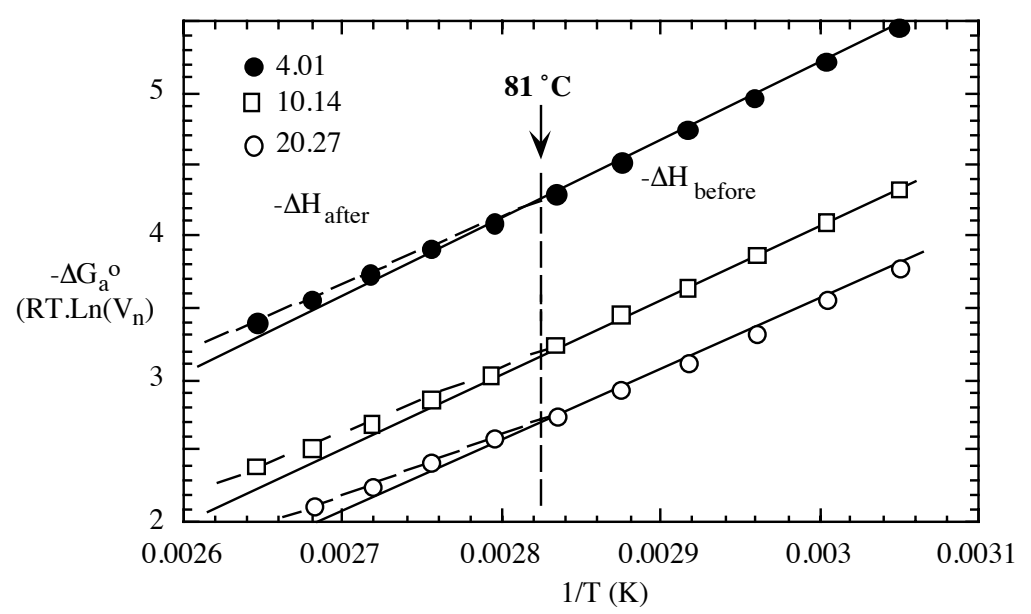

Fig. 5. Variation of the $-\Delta G_{a}^{\circ} / T$ with $1 / \mathrm{T}$ for T30 silica at 3 different molecular impregnation ratios: $4.01,10.14$ and $20.27 \mathrm{MU} / \mathrm{nm}^{2}$.

for both polymers, the evolutions are different when the impregnation ratio becomes higher than this critical ratio.

If the evolution observed for PEG is relatively easy to understand: the deposited PEG smoothes at first the surface irregularities of the surface of the primary particles or bound to the junction points between partially coalesced primary particles, leading to a rapid decrease of the specific surface area. Then, when all the surface roughnesses are filled, the contribution of the increase of a smooth thick film of polymer contributes much slightly to the decrease of the specific surface area.

On the contrary, the particular behaviour of the PS can only be explained if we admit that this polymer is unable to fit closely the silica surface leading to a more rapid plugging of the internal porosity of the aggregate. Hence a rapid decrease of the specific area over the critical coverage ratio will be observed.

\subsection{Study of the evolution of the polymer glassy temperature with the impregnation ratio}

The dispersive component is mainly sensitive to the progressive surface coverage of the silica surface. On the contrary, when having a look to the glassy temperature of the adsorbed polymer, one will have access to the way whom the solid surface influences the mobility and/or the conformation of the polymer alone.

IGC is a convenient method for the determination of the glassy transition temperature $\left(t_{\mathrm{g}}\right)$ of a thin film of polymer deposited on a surface of the solid [8]. At a given impregnation ratio, it is possible to measure the retention time of a given probe at different temperatures. The chosen probe was $n$-heptane. So the variation of the impregnation ratio allows plotting the variation of the free energy as a function of the temperature. In the case of PVC, the variations of $-\Delta G_{a}^{\circ} / T$ versus the inverse of the temperature show two straight lines with a break point in all the curves obtained with the different impregnation ratios of polymer (Fig. 5).
This break point appears at a temperature of $81^{\circ} \mathrm{C}$, the normal glassy transition temperature for PVC. The $t_{\mathrm{g}}$ is observed for all the impregnation ratios studied and is independent of the amount of polymer. So, even if the polymer does not cover the whole surface of the solid it is possible to measure the glassy transition temperature.

After a least square linearisation of the experimental points, the slope of each straight line was measured that are related to the enthalpies of adsorption of the $n$-heptane before and after the glassy transition temperature. The evolution of the adsorption enthalpies of $n$-heptane with all the different impregnation ratios studied are shown in Fig. 6.

The plot (Fig. 6) of the $\Delta H$ values with the ratio of polymer shows three types of behaviour which are the same for the temperatures below and above the glassy transition temperature.

In the first zone, called A, the amount of PVC deposited on the surface is not enough to form a continuous film on the surface, so we observe the adsorption of an isolated macromolecule on the surface of the solid (Fig. 7).

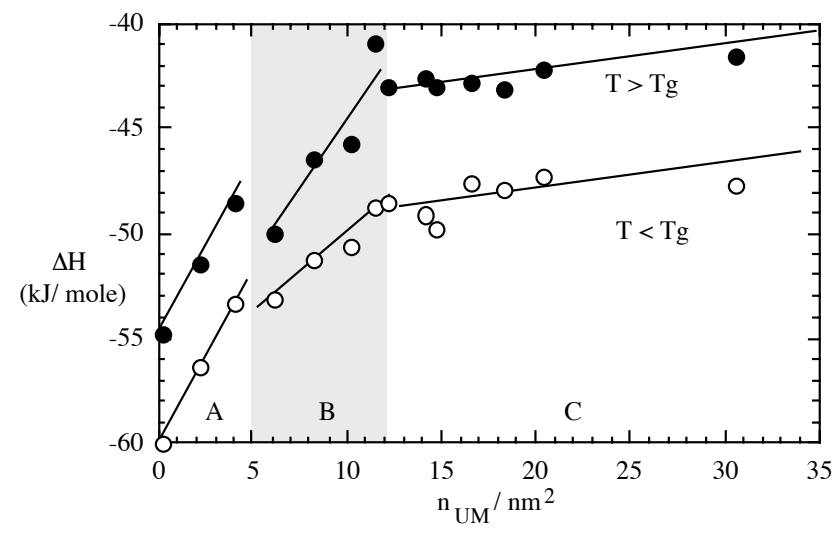

Fig. 6. Variation of the enthalpies of adsorption with molecular impregnation ratios $\left(n_{\mathrm{MU}}\right)$ of PVC impregnated on T30 silica samples. 


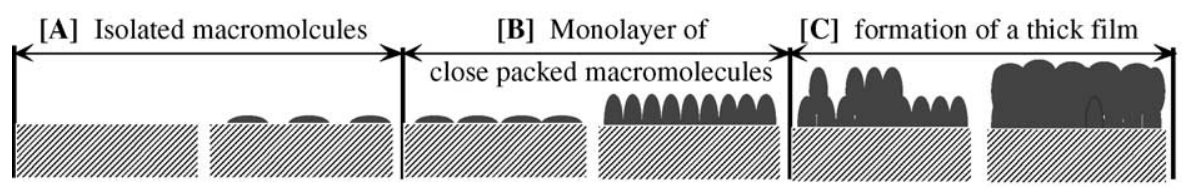

Fig. 7. Schematic representation of the three modes of adsorption.

In zone $\mathrm{B}$, the macromolecules form a 'monolayer of macromolecules', that says that the macromolecules are now in close contact at the surface forming a continuous film.

Finally, in zone $\mathrm{C}$, the impregnation ratios are so high that the macromolecules form a thick film at the surface. The thickness of this film is considered to be constant at any point on the surface. The $\Delta H$ is nearly constant. The same observation were done recently by Hamdi and co workers. that have studied the behaviour of PPMA adsorbed on the same T30 fumed silica [9].

\section{Conclusion}

IGC-ID allows the study of the surface properties of two fumed silicas impregnated with different polymers. The interactions between the polymers and the silica are affected not only by the surface of the solid but also by the structure and conformation of the polymer on the surface of the solid. This conformation depends on the bulkiness of the branch of the polymer. IGC-ID allows an estimate of the number of monomer unit per nanometer square necessary to form a monolayer at the surface of the solid.

IGC-ID is also a useful method for examining the behaviour of a polymer adsorbed on a solid surface and in particular to determine glassy transition temperature. This study highlights three kinds of adsorption corresponding to an isolated macromolecule, close-packed macromolecules and the formation of a thick film of polymer on the surface of the solid.

To conclude, coupling IGC-ID and controlled surface modification through polymer adsorption is a powerful method for obtaining information on the surface of a solid.

\section{References}

[1] J.B. Donnet, T.K. Wang, Y.J. Li, H. Balard, G.T. Burns, Rubber Chem Technol. 73 (2000) 634.

[2] M.P. Comard, R. Calvet, J.A. Dodds, H. Balard, J. Chromatogr. A 969 (2002) 93.

[3] A.P. Legrand, The Surface Properties of Silicas, John Wiley \& Sons, New York, 1998.

[4] E. Papirer, Adsorption on Silica Surfaces, Elsevier, Amsterdam, 2000.

[5] A.P. Legrand, B. Bresson, C. Carteret, A. Burneau, H. Barthel, H. Balard, in: Proceedings of Conference Silica 2001, Mulhouse, France, September 3-6, 2001.

[6] H. Barthel, F. Achenbach, H. Maginot, Surface textural studies of an active silica filler, in: Proceeding of Mineral and Organic Functional Fillers in Polymers International Symposium, Moffis-93, Namur, Belgium, April 13-16, 1993, p. 301.

[7] H. Balard, E. Papirer, A. Khalfi, H. Barthel, J. Weis, in: Norbert Auner et Johann Weis (Eds. ), Organosilicon Chemistry, vol. 4, Wiley, Weinheim, Germany, 2000, p. 773.

[8] B. Li, Rubber Chem. Technol. 69 (1996) 347.

[9] S. Hamdi, B. Hamdi, Z. Kessaissia, H. Barthel, H. Balard, J.B. Donnet, J. Chromatogr. A 969 (2002) 143. 